\section{Disease awareness campaigns turn healthy people into patients}

\author{
Owen Dyer London
}

Media and advertising campaigns that apparently aim at increasing public awareness of underdiagnosed illnesses are really marketing tools for drug companies in search of new customers, say a group of authors and researchers who met in Australia this week for a conference on "disease mongering."

The conference on disease mongering, held in Newcastle, Australia, was timed to coincide with a theme issue of the journal PLoS Medicine, published by the US Public Library of Science (PLoS).

April's issue of PloS Medicine carries 11 peer reviewed articles on disease mongering, which is defined by this month's guest editors as "the selling of sickness that widens the boundaries of illness and grows the markets for those who sell and deliver treatments."

The issue's guest editors, David Henry of the University of Newcastle, Australia, and the journalist Ray Moynihan, a con- tributor to the $B M J$, are also the organisers of the conference. They argue that the corporate sponsored creation of disease turns healthy people into patients, wastes precious resources, and risks iatrogenic harm.

Dr Henry described a de facto alliance between pharmaceutical marketers, journalists, and patient advocacy groups. "They aren't consciously working together, but they have converging interests," he said.

Patient advocacy groups, often funded by the drug industry, become willing partners in the promotion of disease, said Mr Moynihan.

Among the diseases highlighted in PloS Medicine as subjects of disease mongering campaigns are male and female sexual dysfunction, attention deficit hyperactivity disorder, bipolar disorder, and restless legs syndrome.

In one of the articles Steven Woloshin and Lisa Schwartz of Dartmouth Medical School in New Hampshire reviewed newspaper coverage of restless legs syndrome, which began to attract media attention in the United States soon after GlaxoSmithKline launched an awareness campaign in 2003.

The company, which had recently begun testing its drug ropinirole (Requip) in patients with restless legs syndrome, issued a press release describing

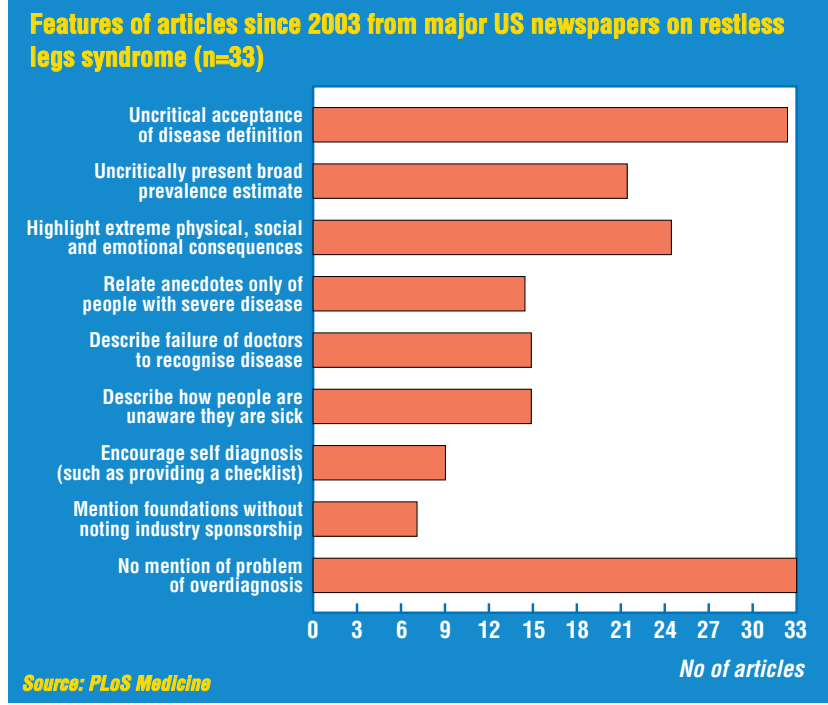

the condition as widespread and underdiagnosed.

The article's authors analysed 33 newspaper articles focused on the disease that were published since the company's campaign. They found that journalists uncritically accepted high estimates of prevalenceoften based on poor evidenceand overstated the benefits of treatment.

Dr Woloshin said that for journalists such a story contains "irresistible elements: big public health crisis, doctors missing diagnoses, a miracle drug available."

He said, "In general, health reporting often lacks sufficient scepticism, so it's not surprising that the claims about restles legs and ropinirole get repeated in an uncritical way." Administration approved ropinirole as a treatment for restless legs syndrome last year, and the disease is now the subject of a GlaxoSmithKline advertising campaign aimed at US consumers. The advertisements encourage the public to see a doctor, without mentioning any specific drugs.

These campaigns are often accompanied by aggressive marketing to doctors of the drug itself, said Mr Moynihan. He said that such advertising is "insidious, it's often invisible, and any serious health department has to start regulating it."
The US Food and Drug

\section{UK launches panel to tackle research misconduct}

Andrew Cole London

A new independent body to tackle biomedical research misconduct in the United Kingdom was launched this week-but its powers will be limited to providing advice and promoting good practice.

The UK Panel for Health and Biomedical Research Integrity has been initially set up as a three year project, and its first priority will be to develop a code of practice applicable to universities, the NHS, and industry.

The panel will also support whistleblowers reporting cases of alleged research fraud in addition to offering training, seminars, and advice on how to investigate suspected cases of research malpractice.

But the panel, chaired by Ian Kennedy, a leading expert in medical ethics and chairman of the NHS watchdog, the Healthcare Commission, will not be able to investigate research misconduct itself. This will remain the responsibility of the employer or research sponsor. Instead, its functions will be "promotional and advisory."

A number of high profile cases of alleged research fraud in the UK recently have related to plagiarism or falsification of data. A survey of universities in 2004 by Universities UK found that four out of 10 had dealt with allegations of research misconduct in the previous five years and almost half of these cases were in health and biomedical research (BMJ 2005;330:616).

The UK's research community needed to show its integrity in the way it conducted its research, saic Professor Kennedy, who warned of the danger of a public backlash if nothing was done. "The poor practice and misconduct of a few [can] undermine public confidence and can put patients and volunteers at risk."

Michael Farthing, pro-vice chancellor for medicine at the University of London, and a driving force in setting up the research panel, said that producing robust guidance on good practice would be top of the new body's priorities, with a first draft expected later this year.

He accepted that some would complain that the new body had no teeth. "But the aim of this body is to sharpen the teeth of the universities and NHS organisations." The existence of the panel would make it more difficult for an organisation to ignore an allegation or concern.

But the self regulatory approach was rejected by Peter Wilmshurst, consultant cardiologist at Royal Shrewsbury Hospital and a long standing campaigner against research misconduct. "I am concerned that, like any form of self regulation, there will be a whitewash," he said. "The fact is that any body that regulates itself, such as the [General Medical Council], tends not to produce findings that the public can have confidence in." A completely independent organisation was needed.

See www.rio.ac.uk. 